\begin{tabular}{|l|}
\hline Cedecea neteri \\
\hline - enterobacteriaceae \\
- facultative anaerobe \\
- rod-shaped \\
- causes of endocarditis \\
patient
\end{tabular}

been characterized on the basis of DNA/DNA hybridization experiments and phenotypic differences: $C$ davisae, $C$ lepage $i, C$ neteri and two unnamed ones. Only one case of human bacteraemia due to a strain of Cedecea has been reported thus far, ${ }^{2}$ in which three of four blood cultures from a patient with possible endocarditis were positive. The patient recovered after treatment. The findings supported a com-

1 Grimont PAD, Grimont F, Farmer III JJ, Asbury MA Cedecea davisae gen. nov, sp. nov. Cedecea lapagie sp. nov. new entrobacteraiaceae from clinical specimens. Int $\mathfrak{f}$ Syst Bacteriol 1981; 31: 317-26.

2 Farmer III JJ, Sheth NK, Hudzinsky JA, Rose HD, Asbury MF. Bacteremia due to Cedecea neteri sp. nov. $f$ Clin Microbiol 1982; 16: $775-8$. munity-acquired origin for this episode rather than a nosocomial infection.

Our patient suffered a fatal episode of septic shock during a severe acute flare-up of SLE including leg thrombosis, acute renal failure requiring dialysis, and respiratory failure. Although we administered high doses of immunosuppressive drugs and plasmapheresis the evolution was fatal. Hypotension may also have contributed to the acute renal failure.

Cedecea neteri appears to have been the causative agent of the final events. It was probably a nosocomial infection in an immunosuppressed patient. It is well known that patients with SLE, particularly those given long-term immunosuppressive therapy, are predisposed to severe infections., ${ }^{3,4}$ Very little is known about the role of Cedecea in human disease, as our patient illustrates. This agent may gain status as an opportunistic pathogen.

3 Hellman DB, Petri M, Whiting-O'Keefe Q. Fatal infection in systemic lupus erythematosus. The role of opportunistic pathogens. Medicine 1987; 66: 341-8.

4 Kattwinkel N, Cool L, Agnello V. Overwhelming fatal infection in a young woman after intravenous cyclosphosphamide therapy for lupus nephritis. $\mathcal{f}$ Rheumatol 1991; 18: $79-81$.

\title{
Medical Anniversary WINSTON CHURCHILL, 2 MARCH 1944
}

(Sir) Winston Churchill (1874-1965) addressed the Royal College of Physicians on two occasions. On this wartime day he was able to reassure the assembly that he had recovered from pneumonia due to the medical attention he had received from Lord Moran, Professor JG Scadding and Dr Evan Bedford. His second address at the Royal College of Physicians was to present his friend and physician, Lord Moran, with Moran's portrait by Pietro Annigoni. This masterly painting hangs on the ground floor of the College alongside portraits of other recent presidents. Churchill had close links with the medical profession through Moran and became honorary FRCS (1943), FRCP (1951) as well as an earlier FRS (1941). 